NASA Technical Memorandum 107298

\title{
Design of a Power Management and Distribution System for a Thermionic-Diode Powered Spacecraft
}

Greg L. Kimnach

Lewis Research Center

Cleveland, Ohio

Prepared for the

31st Intersociety Energy Conversion Engineering Conference cosponsored by IEEE, AIChE, ANS, SAE, AIAA, and ASME Washington, D.C., August 11-16, 1996

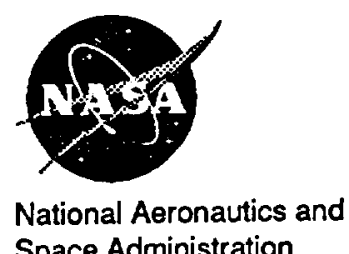

Space Administration 


\title{
DESIGN OF A POWER MANAGEMENT AND DISTRIBUTION SYSTEM FOR A THERMIONIC-DIODE POWERED SPACECRAFT
}

\author{
Greg L. Kimnach \\ NASA Lewis Research Center \\ 21000 Brookpark Road \\ Cleveland, $\mathrm{OH} 44135$ \\ MS 301-5
}

\begin{abstract}
The Electrical Systems Development Branch of the Power Technology Division at the NASA Lewis Research Center in Cleveland, Ohio is designing a Power Management and Distribution (PMAD) System for the Air Force's Integrated Solar Upper Stage (ISUS) Engine Ground Test Demonstration (EGD). The ISUS program uses solar-thermal propulsion to perform orbit transfers from Low Earth Orbit (LEO) to Geosynchonous Orbit (GEO) and from LEO to Molnya. The ISUS uses the same energy conversion receiver to perform the LEO to High Earth Orbit (HEO) transfer and to generate on-orbit electric power for the payloads. On-orbit power generation is accomplished via two solar concentrators heating a dual-cavity graphite-core which has Thermionic Diodes (TIDs) encircling each cavity. The graphite core and concentrators together are called the Receiver and Concentrator (RAC). The TID-emitters reach peak temperatures of approximately $2200 \mathrm{~K}$, and the TID-collectors are run at approximately $1000 \mathrm{~K}$.

Because of the high Specific Impulse $\left(\mathrm{I}_{\mathrm{pp}}\right)$ of solar thermal propulsion relative to chemical propulsion, and because a common bus is used for communications, GN\&C, power, etc., a substantial increase in payload weight is possible. This potentially allows for a stepdown in the required launch vehicle size or class for similar payload weight using conventional chemical propulsion and a separate spacecraft bus.

The ISUS power system is to provide $1000 \mathrm{~W}_{\mathrm{e}}$ at $28+/-$ $6 \mathrm{~V}_{d c}$ to the payload/spacecraft from a maximum TID generation capability of $1070 \mathrm{~W}_{\mathrm{e}}$ at $2200 \mathrm{~K}$. Producing power with this quality, protecting the spacecraft from electrical faults and accommodating operational constraints of the TIDs are the responsibilities of the PMAD system. The design strategy and system options examined along with the proposed designs for the Flight and EGD configurations are discussed herein.
\end{abstract}

\section{INTRODUCTION}

USAF's Phillips Laboratory is in the process of designing an ISUS vehicle $[1,2]$. The primary purposes of the upper stage vehicle are basically four-fold:

1) To reduce the required launch vehicle class for a given payload weight.

2) To combine the propulsion and on-orbit electrical power generation into a single "bimodal" system.
3) To use TIDs, mounted on a graphite receiver, to convert heat energy into electrical energy and thereby power both the spacecraft and the payloads. Consequently, there is not a "dispensable" power system associated with a dedicated launch orbit transfer vehicle, thereby increasing the available payload weight.

4) To demonstrate the viability of a solar bimodal power and propulsion system for military and commercial spacecraft which can accommodate a 30-day orbit transfer from LEO to final orbit

The USAF/Phillips Lab initiated a 6-month design effort in January 1995. This design effort required an exhaustive series of trade studies for the entire vehicle-including the PMAD system. At the conclusion of the study, it was determined that certain technical aspects of the vehicle subsystems designs be demonstrated on the ground before any commitment was made to the development of a flight demonstrator. Part of the technologies being developed for the EGD is the PMAD system.

The results of the Phase 1 design effort, impacts of the EGD requirements and specifications upon the EGDPMAD design, and a proposed PMAD flight system are discussed.

\section{PMAD REQUIREMENTS}

The power distribution system requirements--both baselined and derived for the Phase 1 design effort--for the ISUS program are divided into thee primary areas: Power Quality, RAC, and Operational requirements.

1) Power Quality requirements are:

i) The Loads Interface Bus (LIB) is capable of supplying $1 \mathrm{~kW}_{\mathrm{e}}$ user loads.

ii) The LIB voltage is $28+1-6 V_{\text {dc }}$.

iii) In the event of the "loss" of half the receiver, $40 \%$ of the rated power shall be deliverable.

iv) TID failures and receiver cooling will have to be accommodated by the PMAD system.

2) The RAC requirements which impact the PMAD design are:

i) Each half of the dual-cavity RAC shall be circumscribed by a 30-TID string and these strings shall be paralleled at the outputs. 
ii) Individual TIDs, operating at an emitter temperature of $2200 \mathrm{~K}$ shall have a maximum cell voltage of $1.1 \mathrm{~V}$ and be capable of producing $35.7 W_{\mathrm{e}}$. Thus, the maximum power generation capability of the TID strings is a combined $1070 \mathrm{~W}_{e}$, and the maximum TID-string voltage shall be approximately $34 \mathrm{~V}_{\mathrm{dc}}$.

iii) At the end of eclipse, the thermal energy storage of the RAC shall be such that the TID output voltage shall be sustained at $18 \mathrm{~V}_{\mathrm{dc}}$.

3) The Operational requirements are:

i) The PMAD system must ensure that the total load, as seen by the TID source, not exceed $1070 \mathrm{~W}_{\mathrm{e}}$. ii) The total load on the TIDs should be maintained such that the energy balance equation is satisfied. This ensures that the TIDs shall not overheat, thus reducing their useful life.

iii) Because the TID emitters are thermally shielded during LEO and orbit transfer, a Photovoltaic \& Battery (PV\&B) subsystem must be included to power the spacecraft.

iv) The PV\&B subsystem shall be made as small as possible, so that the focus of the spacecraft power system is thermionic generation.

Having defined the power system requirements and specifications, the preliminary design of the PMAD system for both the EGD and flight systems began with a series of trade studies.

\section{TRADE STUDIES}

Power distribution systems can either be regulated or unregulated. A regulated bus is required for those systems which are supplied by a source having poor power quality specifications. An unregulated bus can be used on those systems that are supplied by a power source which maintains the bus within the power quality requirements of the loads. An unregulated bus is an attractive option because it minimizes weight and is appropriate if, and only if, the following conditions hold:

1) The source, insofar as the loads are concerned, is ideal. This implies that over wide operating conditions the source maintains its output voltage within specifications. However, much like a terrestrial power grid with insufficient "spinning reserves", the TID output voltage will decrease under a variety of conditions--including thermal storage limitations of the receiver, thermal-to-electrical conversion efficiency, and reliability of the TIDs.

2) The loads are bounded and well behaved. That is, the load profile is deterministic and the source has been sized to accommodate all contingencies.

Condition (2) should--by design--hold for the ISUS program; however, condition (1) does not. As a result, an unregulated distribution system can qualitatively be deemed unacceptable. However, although deemed unacceptable, it was desired to develop an unregulated bus as a baseline of comparison for regulated options.

\section{Unrequlated Loads Interface Bus Options}

As a baseline of comparison, an unregulated distribution system was analytically developed and analyzed over the expected operating range of the TID voltages. This system was designed to maximize the system efficiency and minimize the weight, given that the TIDs are operating nominally (i.e. at $2200 \mathrm{~K}$ and $28 \mathrm{~V}_{\mathrm{dc}}$ ). The resulting end-to-end efficiency is $92.7 \%$ and the system weight (consisting of the harnesses, connectors, and power hardware) is approximately $80.1[\mathrm{lbs}]$. Because the system efficiency decreases substantially as the TID voltage decreases (see Figure 2), regulators were next investigated.

While technically not regulators, a capacitor and battery were investigated first. A capacitor, placed on the LIB, cannot ensure that the $28+/-6 V_{d c}$ requirement will be met. While a capacitor can attenuate voltage transients, it cannot store enough energy, unless it were sized prohibitively large, to maintain the bus voltage within specifications as the TID voltage drops below $22 \mathrm{~V}_{\mathrm{dc}}$. The second option is the selection of a battery. Again, while a battery can stiffen the bus voltage and "regulate" it under a wider range of operating conditions, unless it were over-sized or installed with a charge/discharge controller, it cannot maintain the bus as its state of charge decreases. Furthermore, by placing a battery on the LIB, the primary focus of the TIDs as a reliable and viable source would be diminished, therefore the battery also is not programatically acceptable. As a result, active passive "regulators" were investigated.

Typical isolated, switching-regulators which were considered included buck, boost, and buck/boost. Each topology has a relatively high efficiency (i.e., approximately 85-to-90\%); however, each suffers a disadvantage compared to the NASA LeRC-developed Series Connected Boost Unit (SCBU) [3]. The major disadvantage of each common topology is that all of the power must be processed by the respective converter. Increased power processing increases the size and weight of the converter. Since a goal of the PMAD system design was one of minimizing its weight in favor of greater payload capacity, the SCBU was selected as the LIB regulator.

\section{The Series Connected Boost Unit Technology}

The SCBU (see Figure 1) is a buck regulator "floating" on the input voltage source--much like an autotransformer. The major benefits of the SCBU topology are an increased power transfer efficiency and its provision for single fault tolerance. Efficiency levels of $96+\%$ are readily achievable by selecting the 
appropriate boost voltage level and dc-dc converter, because the regulator only processes a fraction of the total power. Single fault tolerance is achieved because, if the SCBU fails (e.g., the input bridge opens), there is an electrical path around the SCBU. This fault tolerance, of course, implies a loss of regulation.

The SCBU operates by adding voltage to the input. If the input voltage is less than the desired bus voltage, the SCBU adds voltage; if the input voltage is above the desired bus voltage, the SCBU is bypassed Considering only the $\mathrm{dc}-\mathrm{dc}$ conversion efficiency, the SCBU's ideal efficiency as a function of the dc-dc converter efficiency is given in Equation 1.

$$
\eta_{S C B U}=\frac{1+\frac{V_{\text {boost }}}{V_{\text {source }}}}{1+\frac{V_{\text {boost }}}{V_{\text {source }}{ }^{*} \eta_{d c / d c}}}
$$

\section{SCBU Efficiency} Equation 1

As the SCBU boost approaches zero boost, the conversion efficiency approaches $100 \%$. That is, the dcto-dc converter is being bypassed (Vout = Vin), hence the efficiency is ideally $100 \%$. However, the SCBU behaves more like a "lossy" short, because the dc-dc converter's output bridge introduces transmission losses and its housekeeping power requirements. As the SCBU boost approaches its maximum design value, the SCBU configuration efficiency approaches values in the mid-toupper $90 \mathrm{~s} \%$ range.

$$
\begin{aligned}
& \text { DC/DC converter efficiency: Effd: }=0.85 \\
& \text { Source Voltage: } \quad V_{s}: 18 . C \\
& \text { Boost Voltage: } \mathrm{Vb}:=10.0 \\
& \text { SCBU Efficiency: } \frac{1+\frac{\mathrm{Vb}}{\mathrm{V}_{\mathrm{s}}}}{1+\frac{\mathrm{Vb}}{\mathrm{V}_{s} \cdot \text { Effd }}}=0.941
\end{aligned}
$$

\section{Example 1}

For the ISUS program, the SCBU design is based upon the assumption that the maximum anticipated boost voltage will be $10 \mathrm{~V}_{\mathrm{dc}}$ at rated load. (Recall that the minimum TID voltage, under worst-case operating conditions, shall be $18 \mathrm{~V}_{\mathrm{dc}}$ and the LIB is to be regulated at $28 \mathrm{~V}_{\mathrm{dc}}$ nominal.) Thus, it is seen in Example 1 that the SCBU will operate at approximately $94 \%$ efficiency with a boost voltage of $10 \mathrm{Vdc}$. Compare this to the $\mathrm{dc}-\mathrm{dc}$ converter efficiency of $85 \%$.

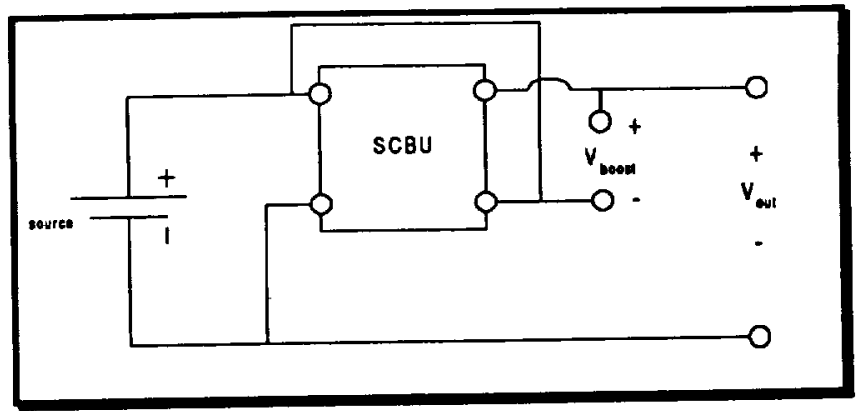

\section{SCBU Topology}

Figure 1

The Power Boost Ratio (PBR) defines the maximum power processed by the SCBU's dc/dc converter during worst-case operation, and is defined as:

$$
\text { Power Boost Ratio } \equiv \frac{P_{\text {load }}}{P_{d c / d c}}=\frac{V_{\text {out }}}{V_{\text {boost }}}
$$

\section{Power Boost Ratio}

Equation 2

Note that as the boost voltage decreases, the PBR increases, implying that the dc-dc converter is processing less power. This is what is desired at nominal (i.e., low boost operation) conditions.

Selecting the required $\mathrm{dc} / \mathrm{dc}$ converter(s) to be used in the SCBU topology is simply a matter of identifying the maximum boost voltage, the rated load, and the desired nominal LIB voltage. Having identified these parameters, Equation 2 is solved for $P_{d c / d c}$. The required converter for the ISUS SCBU is sized based on the PMAD requirements:

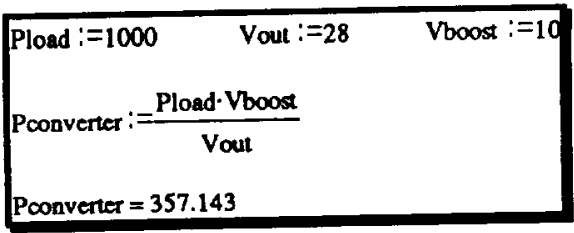

Example 2
Thus, the $\mathrm{dc} / \mathrm{dc}$ converter will process a maximum of $36 \%$ of the rated $1 \mathrm{~kW}_{\mathrm{e}}$ load during maximum boost and will process less power during normal operation. Two $200 \mathrm{~W}_{\mathrm{e}} \mathrm{dc} / \mathrm{dc}$ converters are selected to meet the $357 \mathrm{~W}_{\mathrm{e}}$ power requirement. (Note: SCBU nomenclature provides ratings for the bus power supplied, not the $\mathrm{dc} / \mathrm{dc}$ converters used. As a result, the SCBU used to regulate the LIB is referred to as a $1000 \mathrm{~W}_{\mathrm{e}}$ unit, not $400 \mathrm{~W}_{\mathrm{e}}$ )

\section{The Regulated-TID Loads Interface Bus}

The unregulated system model was then modified to include the SCBU regulator which maintains the LIB at 
$28 \mathrm{~V}_{\text {de. }}$ Both topological proposals were analyzed and compared. From Figure 2 it is seen that as the TID output voltage drops below $26.5 \mathrm{~V}_{\mathrm{dc}}$, the regulated system efficiency is greater than that of the unregulated. When the TID voltage drops to $18 \mathrm{~V}_{\mathrm{dc}}$, the unregulated system end-to-end efficiency drops to $83 \%$ and that of the regulated system drops to roughly $91 \%$. As a result, it is seen that the benefits of the regulated system outweigh the "hit" taken by the additional 10.2[lbs] over the unregulated distribution topology.

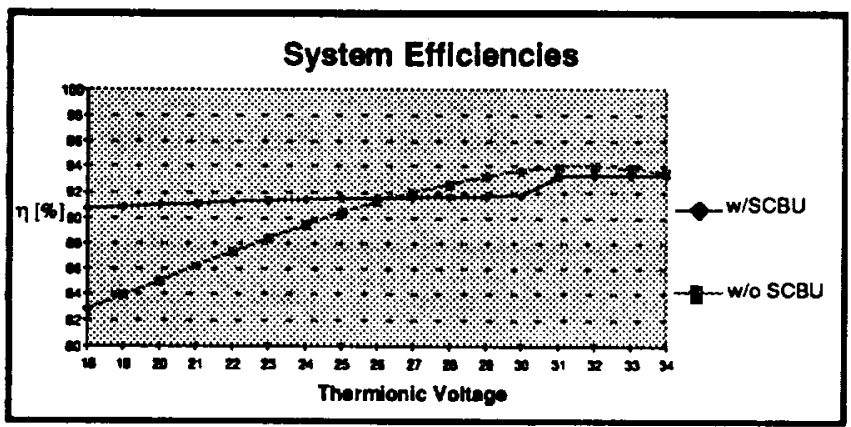

Regulated-versus-Unregulated System Efficiencies Figure 2

\section{FLIGHT PMAD SYSTEM DESIGN PROPOSAL}

The PMAD system design, resulting from the Phase A design effort, consists of five basic elements: the SCBU, the Power Control Module (PCM), the Power Shunt Module (PSM), a Gallium Arsenide (GaAs) photovoltaic array, and a Nickel-Hydrogen $\left(\mathrm{NiH}_{2}\right)$ battery. Table 1 lists the size and weight information of the PMAD system, and Figure 3 is a one-line diagram of the system topology.

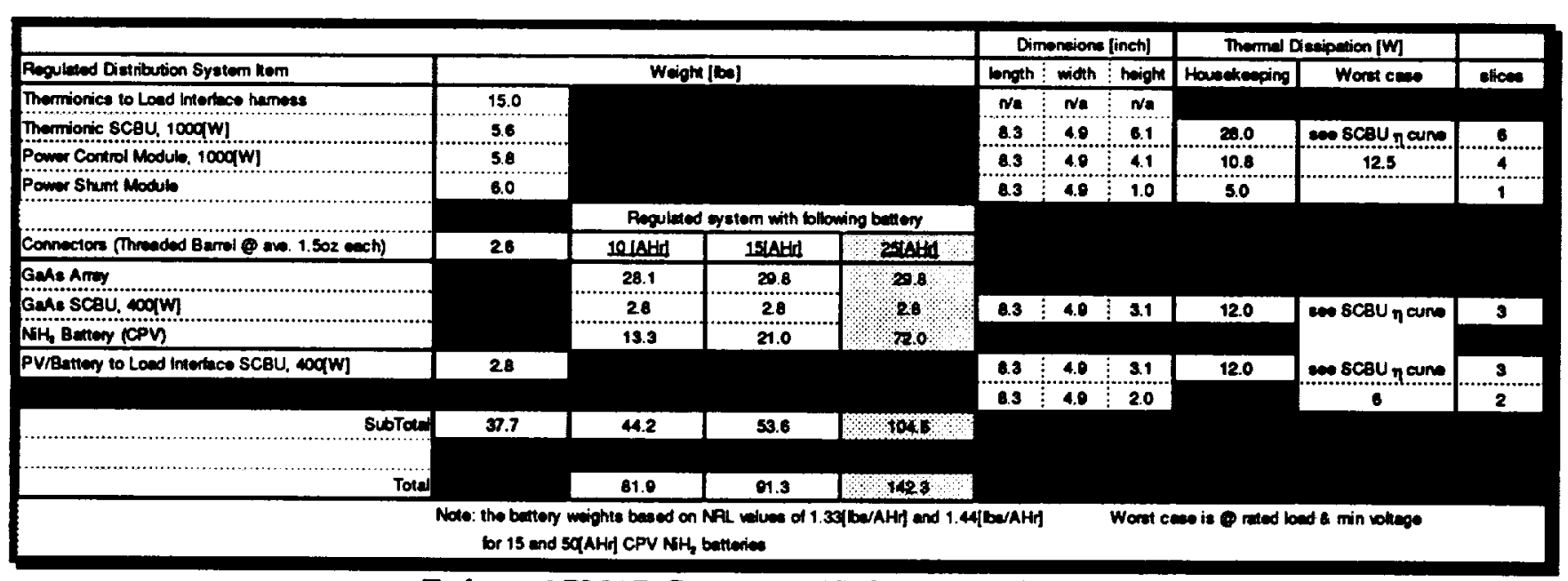

Estimated PMAD Component Weights and Dimensions Table 1

\section{Power Control Hardware}

The first hardware element, the SCBU, is incorporated in thee subsystems on ISUS: as the TID array regulator, as the GaAs PV regulator, and as the $\mathrm{NiH}_{2}$ battery regulator. The SCBUs are sized based on the loads requirements (defined in the mission requirements) during LEO or Molnya orbits. The $1000 \mathrm{~W}_{\mathrm{e}}$ SCBU used to regulate the LIB during normal, on-orbit operation has dimensions of $8.3^{\prime \prime} \mathrm{L} \times 4.9^{\prime \prime} \mathrm{W} \times 6.1$ " $\mathrm{H}$ and weighs 5.6[lbs]. The SCBUs used to regulate the PV and the battery outputs are rated at $400 \mathrm{We}$, have dimensions of $8.3^{\prime} \mathrm{L} \times 4.9^{\prime \prime} \mathrm{W} \times 3.1^{\prime \prime} \mathrm{H}$, and weigh $2.8[\mathrm{lbs}]$.
The second element, the PSM, primarily ensures that the energy balance equation (Equation 3) is satisfied. Energy balance is tantamount to reliable system functions, because the thermal storage of the graphite RAC core is limited and the durability of the TIDs is affected by over-temperature operation. If too little energy is used by the payloads, then the thermal energy entering the RAC is greater than that being consumed. This would result in the RAC temperature increasing and "baking" the TIDs. In order to maintain the Energy Balance during insolation, the PSM, which is a parasitic load bank under the supervisory control of the PMAD control function, is used to shunt power during low 
payload power requirements. The PSM, based on preliminary payload specifications, is sized to shunt $350 \mathrm{~W}_{\mathrm{e}}$ maximum.

$E_{\text {bermal }}$ into $R A C=E_{\text {Loses }}+E_{\text {hermal, ous }}+E_{\text {loads }}$

\section{Energy Balance Equation Equation 3}

The PSM also behaves as a shunt regulator when the TID output voltage exceeds the desired $28 \mathrm{~V}_{\mathrm{dc}}$ bus voltage, which the SCBU cannot control.

The PCM is the interface of payloads to the LIB. This element nominally contains the solid-state switches, fuses, voltage and current sensors, and a communications interface. The solid state switches incorporate $v^{2} t$ trip curves and are current limiting devices. If an excessive amount of load is placed upon the system, then the core will cool more quickly--thus reducing the duration into eclipse which load can be maintained without load shedding. Ensuring that the TIDs not be heavily loaded is a function of load scheduling and is controlled by the PCM. Furthermore, the PCM is used to isolate faults.

\section{Photovoltaic \& Battery Subsystem Design}

Because the Phase A systems requirements for ISUS require that the TIDs be thermally shielded from the graphite cavity until final orbit is attained, the spacecraft requires a power source subsystem which is to be used only during LEO and orbit transfer. A Photovoltaic \& Battery (PV\&B) subsystem using a GaAs array and a $\mathrm{NiH}_{2}$ battery within a Constant Pressure Vessel (CPV) are selected.

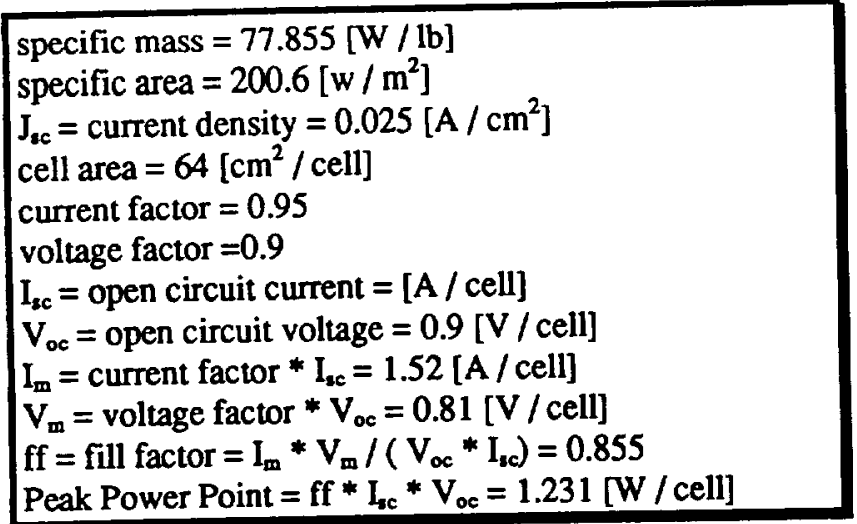

Gallium Arsenide Cell Parameters Table 2

During LEO and orbit transfer, the peak power demand is $220 \mathrm{~W}_{e}$, the maximum eclipse is 36 -minutes and the minimum insolation is 56-minutes. These constraints result in the need for a battery having a $12[\mathrm{~A}-\mathrm{H}]$ capacity. This implies two choices:

1) Select a $15[\mathrm{~A}-\mathrm{H}] \mathrm{NiH}_{2}$ battery, weighing roughly 21 [lbs]. This has slightly more capacity than is required; however, it has the advantages of a moderate $52 \%$ Depth of Discharge (DoD), it is available, and has been flight proven.

2) Select a $10[\mathrm{~A}-\mathrm{H}] \quad \mathrm{NiH}_{2}$ battery, weighing roughly $13[\mathrm{lbs}]$. Although the weight and volume savings of the smaller battery are significant (i.e., consider launch costs and volume availability for payloads), the $10[\mathrm{~A}-\mathrm{H}] \mathrm{NiH}_{2}$ battery is not available, would require high development costs, and would operate into very deep $86 \%$ DoD cycles.

As a result, the $15[\mathrm{~A}-\mathrm{H}]$ battery is selected. The next requirement is the design of the PV array, which is used to recharge the battery and service the payloads during the orbit-transfer insolation periods. The array sizing requirements for an unregulated and a regulated array output are discussed next.

\section{Unregulated GaAs Array Sizing}

GaAs cell parameters are given in Table 2 and the required array for a self-charge regulating battery is determined as follows. Based on a battery efficiency of 0.75 and the eclipse load requirements, the energy required to recharge the battery is $176\left[\mathrm{~W}_{\mathrm{e}} \mathrm{H}\right]$. When the battery is fully charged, the array will service the bus at approximately the battery's maximum Open Circuit Voltage $\left(\mathrm{V}_{\mathrm{oc}}\right)$ of $27.9 \mathrm{~V}_{\mathrm{dc}}$; furthermore, when the battery is fully discharged, the array should operate at the peak power point to service the $220 \mathrm{~W}_{\mathrm{e}}$ payloads and battery. Thus the required peak power point is:

$$
\left[176\left[\mathrm{~W}_{\mathrm{e}}{ }^{*} \mathrm{H}\right]+220\left[\mathrm{~W}_{\mathrm{e}}\right]^{*} 0.92[\mathrm{H}]\right] / 0.92[\mathrm{H}]=411\left[\mathrm{~W}_{\mathrm{e}}\right]
$$

The array is then physically sized by selecting the number of cells required in series and the number of strings and are found according to Equation 4 . As a result, the unregulated $\mathrm{PV}$ array will have 11 strings with 32 cells/string, which results in a $433 \mathrm{~W}_{\mathrm{e}}$ array having a $2.25 \mathrm{~m}^{2}$ area. However, the maximum available area to surface mount an array on the ISUS vehicle is $2.2 \mathrm{~m}^{2}$, which implies a slightly undersized array. Thus, the unregulated PV array cannot meet the requirements for thorough battery charging.

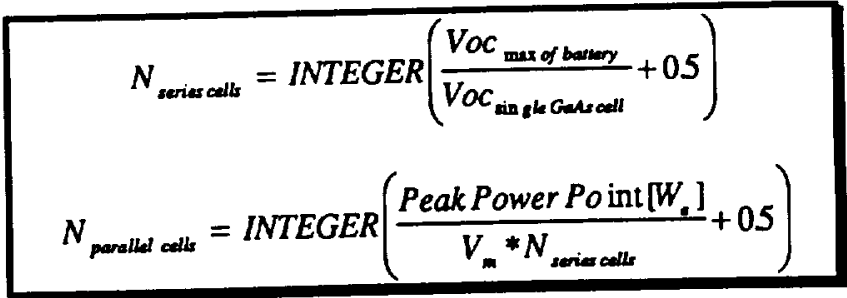

$$
\begin{aligned}
& \text { Required Number of Cells \& Strings }
\end{aligned}
$$

The array can be made smaller by using an SCBU regulator. The advantages of regulating the GaAs array output with an SCBU are that the battery can be fully 
recharged after the array degrades, the charge current profile can be controlled, and the array can be sized roughly $5-10 \%$ smaller at its Beginning of Life (BoL) than an unregulated array.

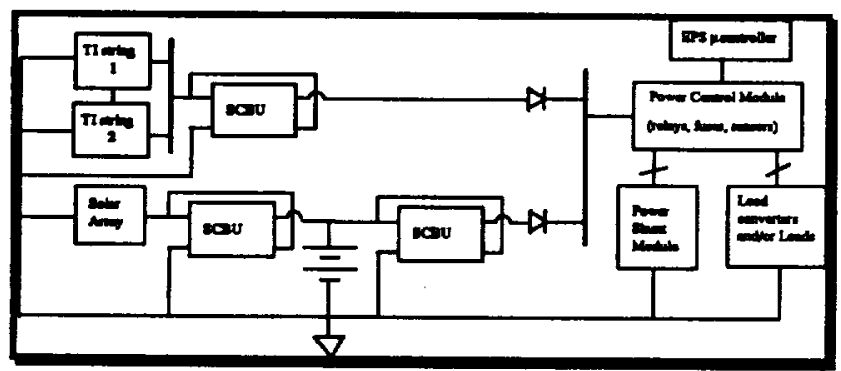

Regulated System Topology

Figure 3

\section{SCBU-Requlated Array Sizing}

The SCBUs for the array and battery are sized using Example 1 and the following rationale. During orbittransfer eclipses, the battery is the sole energy supply and the LIB is to be regulated with an SCBU at $28 \mathrm{~V}_{\mathrm{dc}}$. This implies an approximately constant discharge current of

$$
220\left[\mathrm{~W}_{\mathrm{e}}\right] / 28\left[\mathrm{~V}_{\mathrm{dc}}\right]=7.9[\mathrm{~A}] \text {. }
$$

The maximum battery boost voltage of $5.3 \mathrm{~V}_{\mathrm{dc}}$ occurs when the battery is at its minimum $\mathrm{SoC}$, for which the corresponding voltage is $22.6 \mathrm{~V}_{\mathrm{dc}}$. Thus the SCBU, having approximately $95 \%$ efficiency will process

$$
\left(7.9[\mathrm{~A}] * 5.3\left[\mathrm{~V}_{\mathrm{dc}} \mathrm{J}\right)=43\left[\mathrm{~W}_{\mathrm{e}}\right]\right.
$$

of the total

$$
\left(7.9[\mathrm{~A}] * \mathrm{~V}_{o c, \max }\right)=7.9[\mathrm{~A}] * 27.9\left[\mathrm{~V}_{\mathrm{dc}}\right]=231\left[\mathrm{~W}_{\mathrm{e}}\right]
$$

maximum supplied by the battery. The array must then be sized to supply a constant load current (at the loads interface bus) of 7.9A plus a constant charge-current of $6.8 \mathrm{~A}$ to the battery. This is a total array current of 14.8A. When the battery is fully discharged, a constant charge current of $6.8 \mathrm{~A}$ requires a battery terminal voltage (i.e., PV-SCBU output voltage setpoint) of

$$
\begin{aligned}
6.8[A] * R_{\text {batery }}+ & V_{o c, \min }=6.8[A]+0.355[\mathrm{~W}]+ \\
& 22.6\left[V_{\mathrm{dc}}\right] \\
& =25.03\left[\mathrm{~V}_{\mathrm{dc}}\right]
\end{aligned}
$$

This value indicates that the boost voltage is $2.43\left[\mathrm{~V}_{\mathrm{dc}}\right]$ and the power delivered at the PV-SCBU output is

$$
25.03[\mathrm{Vdc}] * 14.8[\mathrm{~A}]=367.6\left[\mathrm{~W}_{\mathrm{e}}\right] \text {. }
$$

Again, with the SCBU having 95\% efficiency, the array PPP is

$$
367.6[\mathrm{We}] / 0.95=386.9\left[\mathrm{~W}_{\mathrm{e}}\right] \text {, }
$$

which is approximately $6 \%$ lower in power capacity than the unregulated array requirements. (Note that the comparison is made with the $411 \mathrm{~W}_{\mathrm{e}}$ array.) However, since an integer number of cells are required to fulfill both the current and voltage requirements, it is found that the array, given the GaAs cell values, will actually have a Beginning of Life (BOL) PPP of 413.7W. This array requires $2.06 \mathrm{~m}^{2}$.

The overall PMAD system weight is 91.3[lbs]. This includes the PV\&B subsystem, the required harnesses, the SCBUs, the PCM, and the PSM.

\section{ENGINE GROUND TEST DEMONSTRATION}

The EGD, which is to be run in the Vacuum Tank 6 facility at LeRC, is to begin in late early 1997 . However, because of programmatic cost-constraints, the PMAD functional requirements are impacted. The primary objective of EGD is to run the propulsion system continuously for $\mathbf{3 0}$ days to simulate an orbit transfer and to evaluate the cryo/propellant functions. These impacts upon the PMAD tests include:

- Electrical system performance during orbit transfer is not a priority. Therefore, a PV+B subsystem will not be built.

- Only one-half of a RAC--called a RACCET--will be built and tested in Tank 6 . The RACCET limitations impact the requirements upon the PMAD design and development for EGD. Specifically, the output voltage of a RACCET is nominally $14 \mathrm{~V}_{\mathrm{dc}}$, but the load requirements for EGD remain $1000 \mathrm{~W}_{\mathrm{e}}$ at $28 \mathrm{~V}_{\mathrm{dc}}$. This would result in TIDs with twice the current density. As a result, the output voltage of the RACCET must be boosted--yet retain the transient and steady state response of a full TID string so that the baselined SCBU not be redesigned. To this end NASA Lewis is developing a thermionic-diode string simulator, which will be placed in series with the RACCET diodes, thus providing a full $28 \mathrm{~V}_{\mathrm{dc}}$ TID source as seen by the SCBU

The on-orbit testing phase of the EGD has the following PMAD test objectives:

- Collect source impedance data for the TID string.

- Characterize the TID string under transient and steady-state conditions.

- Characterize the SCBU performance when regulating the TID source.

- Characterize the behavior and power quality of the PMAD system under fault conditions.

- Characterize the behavior and power quality of the PMAD system using current-limiting and noncurrent-limiting switches.

- Demonstrate the viability and reliability of the TID source for space applications. 


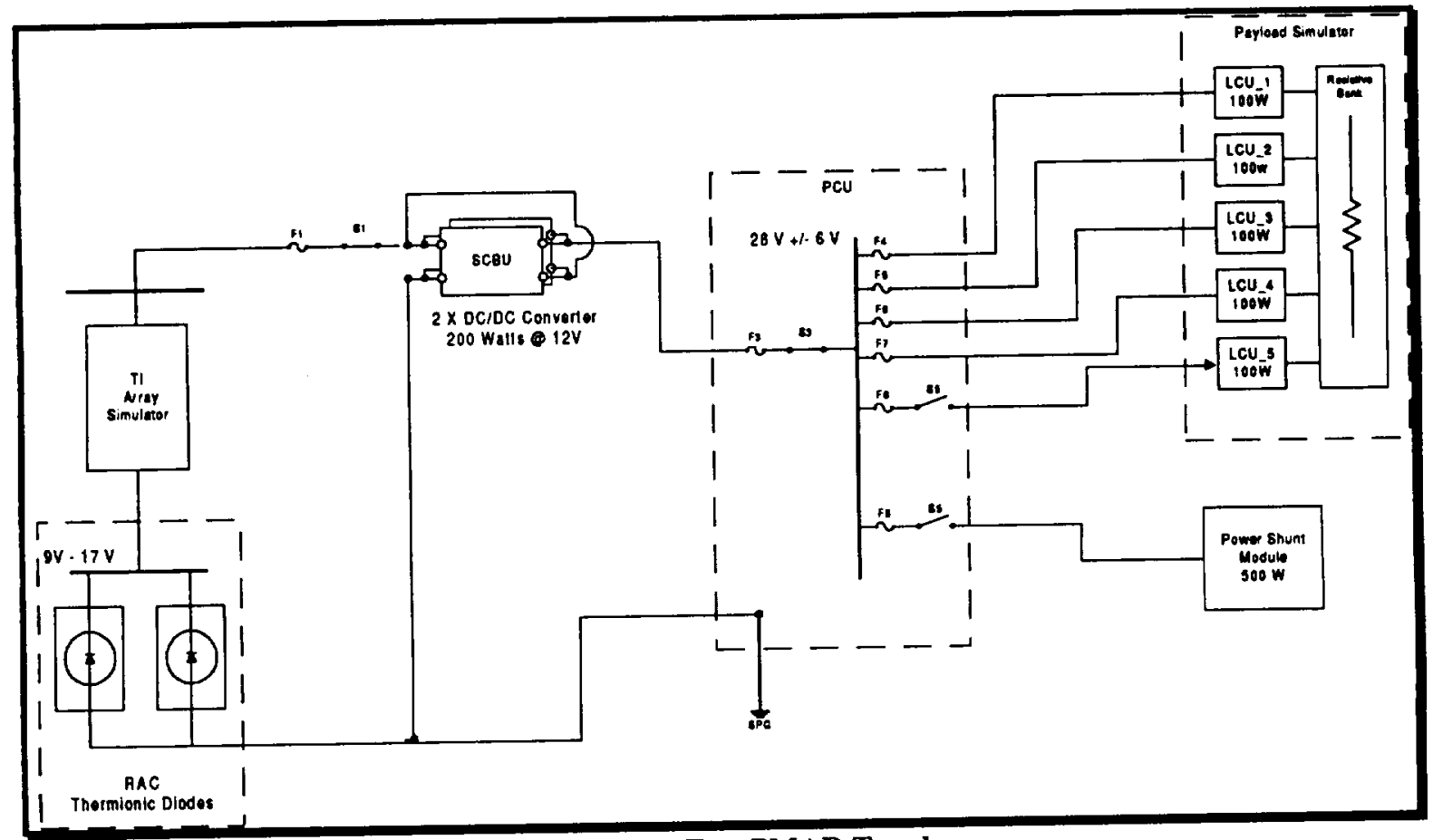

Engine Ground Test PMAD Topology

Figure 4

The SCBU technology, developed for the Photovoltaic Regulator Kit Experiment (PRKE) [4,5], resulted in a $180 \mathrm{~W}_{\mathrm{e}} \mathrm{SCBU}$, based on a $60 \mathrm{~W}_{\mathrm{e}} \mathrm{dc} / \mathrm{dc}$ converter. The $1000 W_{e}$ SCBU, required for the EGD and flight, is presently being designed and will be based on two $200 \mathrm{~W}_{\mathrm{e}}$ $\mathrm{dc} / \mathrm{dc}$ converters paralleled. The PSM design uses commercial load banks and controllers to minimize testdevelopment costs. The PCM design incorporates current-limiting and non-current limiting switches to evaluate the PMAD system performance with a variety of hardware options. Finally, to have a complete PMAD system for EGD, LeRC is also developing a payload simulator which will mimic the on-orbit spacecraft and payloads requirements. This simulator will utilize a mix of typical payload power converters (e.g., $28 \mathrm{~V}_{\mathrm{dc}}$-to$15 \mathrm{~V}_{\mathrm{dc}}$ ).

\section{CONCLUSIONS}

The PMAD system design for ISUS uses the NASA LeRC developed Series Connected Boost Unit to regulate the thermionic-diode generated voltage. The use of an SCBU provides a well-regulated loads interface bus and increases system efficiency as the thermionic output voltage drops, due to insufficient thermal storage, concentrator offpointing, TID failures, or excessive loading. A thermionic-diode simulator is being developed to offset the limitations resulting from the use of a RACCET, being developed for EGD. A Power Shunt Module is being developed to ensure proper and safe operation of the thermionic diodes within the RACCET; a Power Control Module, which provides load switching and fault isolation, is being developed to control loads, to isolate faults, and to characterize impacts upon PMAD system performance by currentlimiting and noncurrent-limiting switchgear; finally, a payload simulator is being developed to mimic the required on-orbit payload requirements. The integration of these elements will result in the testing of an end-toend PMAD system with a thermionic source during EGD.

A photovoltaic/battery subsystem has been designed and proposed for the flight system, but shall not be used in EGD because electrical characterization during orbittransfer is not a goal of EGD. The $1000 \mathrm{~W}_{c}$ PMAD system is to be tested with the thermionic diode source in the Vacuum Tank 6 located at LeRC in Cleveland, $O H$. 


\section{REFERENCES}

${ }^{1}$ Kennedy, Fred G. III and Jacox, Michael G, USAF Phillips Laboratory. "The Integrated Solar Upper Stage (ISUS) Program". ASME95-3628

${ }^{2}$ Kennedy, Fred G. III and Jacox, Michael G, USAF Phillips Laboratory. "Mission Applications of an Integrated Solar Upper Stage (ISUS)". ASME95AP0401.

${ }^{3} \mathrm{http} / / /$ powerweb.lerc.nasa.gov/elecsys/DOC/scbc.html,

4 Anastacio Baez, Ramon Lebron, and Michael Mackin. "The Small Spacecraft Technology Initiative Photovoltaic Regulator Kit Experiment (PRKE)", IECEC 1996.

${ }^{5}$ Button, Robert M. and Baez, Anastacio N. "A Modular Electric Power System Test Bed for Small Spacecraft", AIAA-95-0030, 33rd Aerospace Sciences Meeting and Exhibit, January, 1995. 



\begin{tabular}{|c|c|c|c|c|}
\hline \multicolumn{3}{|c|}{ REPORT DOCUMENTATION PAGE } & & $\begin{array}{l}\text { Form Approved } \\
\text { OMB No. 0704-018B }\end{array}$ \\
\hline \multicolumn{5}{|c|}{ 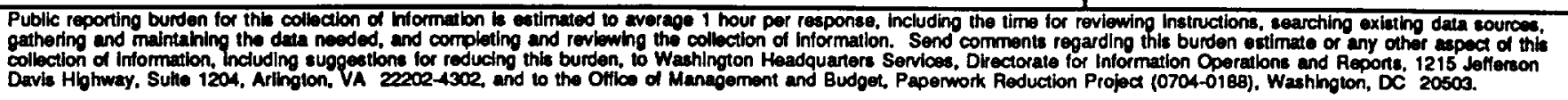 } \\
\hline 1. AGENCY USE ONLY (Leave Dlank) & $\begin{array}{r}\text { 2. REPORT DATE } \\
\text { August } 1996\end{array}$ & \multicolumn{3}{|c|}{$\begin{array}{l}\text { 3. REPORT TYPE AND DATES COVERED } \\
\text { Technical Memorandum }\end{array}$} \\
\hline \multicolumn{4}{|c|}{$\begin{array}{l}\text { 4. TILE AND SUBTILE } \\
\text { Design of a Power Management and Distribution System for a Thermionic-Diode } \\
\text { Powered Spacecraft }\end{array}$} & \\
\hline \multicolumn{3}{|l|}{$\begin{array}{l}\text { 6. AUTHOR(S) } \\
\text { Greg L. Kimnach }\end{array}$} & & \\
\hline \multicolumn{3}{|c|}{$\begin{array}{l}\text { 7. PERFORMING ORGANIZATION NAME(S) AND ADDRESS(ES } \\
\text { National Aeronautics and Space Administration } \\
\text { Lewis Research Center } \\
\text { Cleveland, Ohio } 44135-3191\end{array}$} & \multicolumn{2}{|c|}{$\begin{array}{l}\text { 8. PERFORMANG ORGANIZATION } \\
\text { REPORT NUMBER } \\
\text { E-10376 }\end{array}$} \\
\hline \multicolumn{3}{|c|}{$\begin{array}{l}\text { 9. SPONSORING/MONITOAING AGENCY NAME(S) AND ADDF } \\
\text { National Aeronautics and Space Administration } \\
\text { Washington, D.C. } 20546-0001\end{array}$} & \multicolumn{2}{|c|}{$\begin{array}{l}\text { 10. SPONSORINGMONTTORING } \\
\text { AGENCY REPORT NUMBER } \\
\text { NASA TM-107298 }\end{array}$} \\
\hline \multicolumn{5}{|c|}{$\begin{array}{l}\text { 11. SUPPLEMENTARY NOTES } \\
\text { Prepared for the } 31 \text { st Intersociety Energy Conversion Engineering Conference cosponsored by IEEE, AIChE, ANS, SAE, } \\
\text { AIAA, and ASME, Washington, D.C., August 11-16, 1996. Responsible person, Greg L. Kimnach, organization code } \\
5450,(21) 433-6251 \text {. }\end{array}$} \\
\hline \multicolumn{4}{|c|}{\begin{tabular}{l|l} 
12a. DISTAIBUTIONUAVAILABILTTY STATEMENT & 12b. \\
Unclassified - Unlimited \\
Subject Category 20 \\
This publication is available from the NASA Center for AeroSpace Information, (301) 621-0390.
\end{tabular}} & IBUUTION CODE \\
\hline \multicolumn{5}{|c|}{$\begin{array}{l}\text { 13. ABSTRACT (Maximum } 200 \text { words) } \\
\text { The Electrical Systems Development Branch of the Power Technology Division at the NASA Lewis Research Center in } \\
\text { Cleveland, Ohio is designing a Power Management and Distribution (PMAD) System for the Air Force's Integrated Solar } \\
\text { Upper Stage (ISUS) Engine Ground Test Demonstration (EGD). The ISUS program uses solar-thermal propulsion to } \\
\text { perform orbit transfers from Low Earth Orbit (LEO) to Geosynchronous Orbit (GEO) and from LEO to Molnya. The } \\
\text { ISUS uses the same energy conversion receiver to perform the LEO to High Earth Orbit (HEO) transfer and to generate } \\
\text { on-orbit electric power for the payloads. On-orbit power generation is accomplished via two solar concentrators heating a } \\
\text { dual-cavity graphite-core which has Thermionic Diodes (TIDs) encircling each cavity. The graphite core and concentra- } \\
\text { tors together are called the Receiver and Concentrator (RAC). The TID-emitters reach peak temperatures of approxi- } \\
\text { mately } 2200 \mathrm{~K} \text {, and the TID-collectors are run at approximately } 1000 \mathrm{~K} \text {. Because of the high Specific Impulse } \text { I }_{\text {sp }} \text { ) of solar } \\
\text { thermal propulsion relative to chemical propulsion, and because a common bus is used for communications, GN\&C, } \\
\text { power, etc., a substantial increase in payload weight is possible. This potentially allows for a stepdown in the required } \\
\text { launch vehicle size or class for similar payload weight using conventional chemical propulsion and a separate spacecraft } \\
\text { bus. The ISUS power system is to provide } 1000 \mathrm{~W}_{\mathrm{e}} \text { at } 28+1-6 \mathrm{~V}_{\mathrm{dc}} \text { to the payload/spacecraft from a maximum TiD genera- } \\
\text { tion capability of } 1070 \mathrm{~W}_{\mathrm{e}} \text { at } 2200 \mathrm{~K} \text {. Producing power with this quality, protecting the spacecraft from electrical faults and } \\
\text { accommodating operational constraints of the TIDs are the responsibilities of the PMAD system. The design strategy and } \\
\text { system options examined along with the proposed designs for the Flight and EGD configurations are discussed herein. }\end{array}$} \\
\hline \multirow{2}{*}{\multicolumn{3}{|c|}{$\begin{array}{l}\text { 14. SUBJECT TERMS } \\
\text { Integrated solar upper stage; Power management and distribution }\end{array}$}} & & $\begin{array}{l}\text { 15. NUMBER OF PAGES } \\
10\end{array}$ \\
\hline & & & & $\begin{array}{l}\text { 16. PRICE CODE } \\
\text { A02 }\end{array}$ \\
\hline $\begin{array}{l}\text { SECURTY CLASSIFICATION } \\
\text { OF REPORT } \\
\text { Unclassified }\end{array}$ & $\begin{array}{l}\text { 18. SECURTY CLASSIFICATION } \\
\text { OF THIS PAGE } \\
\text { Unclassified }\end{array}$ & $\begin{array}{l}\text { 19. SECU } \\
\text { OFA }\end{array}$ & & 20. LIMITATION OF ABSTRACT \\
\hline
\end{tabular}

NSN 7540-01-280-5500 